\title{
Análise comparativa dos modelos adotados como referência para a definição dos mapeamentos de referência do Brasil e da Alemanha
}

\author{
Comparative analysis of the models adopted as reference to determine
} reference mappings in Brazil and Germany

Caio dos Anjos Paiva

Raphael Gonçalves De CAMPOS ${ }^{b}$
${ }^{a}$ Doutorando em Giências Geodésicas pela Universidade Federal do Paraná (UFPR). E-mail: anjospaiva@gmail.com
${ }^{\text {b }}$ Doutorando em Ciências Geodésicas pela Universidade Federal do Paraná (UFPR). E-mail: raphageoc@gmail.com

\begin{abstract}
Este artigo apresenta uma discussão acerca dos elementos que compõem o mapeamento de referência realizado no Brasil e sua relação com a sistemática adotada para o mapeamento alemão. Visando a contribuir para ampliar informações a respeito da lógica desenhada como modelo para o caso brasileiro, o comparativo buscou, a partir das semelhanças observadas entre os dois sistemas, identificar quais lacunas do mapeamento topográfico brasileiro poderiam ser preenchidas tomando como exemplo uma referência mundial, como o mapeamento realizado na Alemanha. Entre outros, em função da eficácia do mapeamento germânico, a análise permitiu verificar a importância da definição de uma plataforma capaz de centralizar e unificar os dados geoespaciais de diversos setores. Destacam-se, para o caso brasileiro, os dados advindos dos Cadastros Territoriais Municipais.
\end{abstract}

Palavras-chave: mapeamento de referência, mapeamento topográfico, cartografia.

\begin{abstract}
The article discusses elements that constitute the reference mapping carried out in Brazil and its relation to the system adopted by German mapping. In order to further understand its designed logic as a model for the Brazilian scenario, we compared both systems to identify which gaps of the Brazilian topographic mapping could be amended taking as reference the mapping carried out in Germany. Among others, given the effectiveness of the Germanic mapping, analysis showed the importance of defining a platform capable of centralizing and unifying the geospatial data of several sectors. In the case of Brazil, this includes data from the Cadastros Territoriais Municipais.
\end{abstract}

Keywords: reference mapping, mapping topography, cartography. 


\section{INTRODUÇÃO}

O mapeamento de um país, realizado com a finalidade de fornecer informação espacial para qualquer uso, ou seja, que possa ser utilizado em diferentes contextos, deve compreender as feições visíveis da superfície da respectiva região. Os elementos primordiais desse mapeamento são as cartas topográficas, que, relacionadas conforme suas características, definem um sistema. Logo, ao referido conjunto de elementos e relacionamentos dá-se o nome de mapeamento sistemático.

No Brasil, segundo o Instituto Brasileiro de Geografia e Estatística (IBGE), o mapeamento sistemático congrega o conjunto de procedimentos que têm por finalidade a representação do espaço territorial, por meio de cartas gerais, contínuas, homogêneas e articuladas, em diferentes escalas. Atualmente, a Comissão Nacional de Cartografia (Concar) atribui ao IBGE e à Diretoria de Serviço Geográfico do Exército (DGS) a responsabilidade em definir os procedimentos que resultam na representação do território.

Equivalente ao nosso mapeamento de referência, o termo Vermessungverwaltungen, na Alemanha, segundo a Fédération Internationale des Géomètres, significa a comunhão das organizações, suas ações, incluindo metodologias e equipamentos para o levantamento, processamento e representação de dados cartográficos. Conforme atribuição da Constituição do país, cabe aos estados federados legislar sobre as atividades de Cartografia, Agrimensura e Cadastro. Os serviços de levantamento e representação de ferrovias, defesa, águas e transporte marítimo, por sua vez, são de competência da União. É esta, por meio do Ministério do Transporte, Construção e Desenvolvimento, quem deve incorporar ao mapeamento de referência os trabalhos de levantamento e cartografia relacionados (KUMMER, 2006).

Já de início, observando as responsabilidades das entidades relacionadas às atividades de mapeamento, verificam-se algumas similaridades e diferenças entre o Brasil e a Alemanha. A centralização dos processos de mapeamento por parte do primeiro, que incluem desde a coleta de dados até a elaboração do produto final, ou seja, das cartas topográficas, é verificada no segundo apenas no que concerne à comunhão dos dados, uma vez que cada estado é responsável pelo mapeamento de seu território. Diante disso, a sequência a ser apresentada visa delimitar um panorama que permita definir quais lacunas do mapeamento topográfico brasileiro poderiam, de alguma forma, ser preenchidas tomando como exemplo o mapeamento de referência realizado na Alemanha.

\section{MAPEAMENTO SISTEMÁTICO BRASILEIRO E ALEMÃO: BREVE HISTÓRICO}

A análise histórica do nosso mapeamento remete a um atraso na definição de normativas que permitiram a padronização do conjunto de procedimentos relacionados ao mapeamento de referência. A produção cartográfica regulamentada só iniciou a partir de 1946, com o Decreto $\mathrm{n}^{\circ}$ 9.210, de 29 de abril, cujo objetivo era uniformizar a cartografia nacional. Apesar de o Serviço Geográfico Brasileiro executar levantamentos e mapeamento do território nacional desde a instituição do Decreto $\mathrm{n}^{\circ} 451$ A, de 31 de maio de 1890, toda a produção executada nesse intervalo ocorreu sem qualquer sistematização.

Esse atraso na definição de regulamentações é um dos motivos pelos quais somente em 1962 um documento cartográfico recobrindo toda extensão do nosso território fosse publicado pela primeira vez. Foi a Carta do Brasil ao Milionésimo (ARCHELA, 2008), ou seja, um recobrimento na escala de 1:1.000.000.

Uma vez que cabe à União a responsabilidade de legislar a respeito do planejamento territorial, desde então normativas para a padronização da cartografia nacional vêm sendo implantadas em meio a rupturas governamentais. Um exemplo disso foi a criação da Comissão de Cartografia (Cocar) em 1967. Com sua extinção pelo governo federal em 1990, diversas interações no âmbito do Sistema Cartográfico Nacional foram prejudicadas.

Outro exemplo, também ligado a rupturas, é a reativação da Cocar pelo Ministério do Planejamento e Orçamento, a partir do Decreto $s / n^{\circ}$ de 21 de junho de 1994. Denominada desta vez de Comissão Nacional de Cartografia (Concar), já em 1999, devido à extinção do referido Ministério, a Comissão foi novamente desativada, ressurgindo um ano depois no Ministério do Planejamento, Orçamento e Gestão.

Essa sequência de rupturas e reorganizações administrativas trouxe ao Sistema Cartográfico Nacional (SGN) a incapacidade de atender às demandas dos diferentes usuários de cartografia, sejam eles públicos ou privados. Assim, quando da necessidade de material cartográfico de referência para o planejamento 
em diversos setores, o que ocorre é a contratação de mapeamentos esporádicos em determinadas regiões para atender a propósitos específicos.

Com relação ao mapeamento germânico, anterior à análise das características do seu mapeamento, algumas questões devem ser apresentadas: uma delas é o fato de que, durante séculos, o território alemão se retalhou em grandes e pequenos reinos e principados (HAWERK, 2006). Isso influenciou, consequentemente, as políticas de mapeamento de cada região. A outra diz respeito à divisão político-administrativa da Alemanha atual. Conforme o Comitê Permanente de Infraestrutura de SIG para a Ásia e o Pacífico (PCGIAP), esta só se deu após 1945, com o término da Segunda Guerra Mundial. Somente em 1990, com a reunificação dos 11 estados da zona ocidental da Alemanha com os cinco estados da zona oriental, a República Federal da Alemanha voltou a ter uma única capital - Berlim (PERMANENT COMMITTEE ON GIS INFRASTRUCTURE FOR ASIA E THE PACIFIC, 2003).

Atualmente, cada um dos 16 estados que compõem a República Federal da Alemanha possui uma Assembleia Legislativa. Esta é responsável pela aprovação das leis que regem praticamente todas as áreas do país, com exceção da Defesa e das Finanças (FIGUR, 2012). Incluem-se nessas leis aquelas que regem as atividades de levantamento e representação territorial.

\section{CONSIDERAÇÕES SOBRE O MAPEAMENTO SISTEMÁTICO BRASILEIRO}

Todas as atividades ligadas ao mapeamento sistemático brasileiro, de alguma forma, estão subordinadas a deliberações da Concar. Ela designa os diversos órgãos para realizar e manter as atividades correlacionadas. Neste cenário, são órgãos vinculados à Concar: o IBGE; a DSG; a Diretoria de Hidrografia e Navegação (DHN); o Instituto de Cartografia Aeronáutica (ICA); o Instituto Nacional de Pesquisas Espaciais (Inpe); a Companhia de Pesquisa de Recursos Minerais (CPRM); entre outros.

Incluem-se, ainda, nessa organização os Ministérios: da Marinha; da Guerra; da Aeronáutica; da Agricultura; das Minas e Energia; e a Associação Nacional de Empresas de Aerofotogrametria. Cabe a todos esses, conforme o Decreto-Lei n ${ }^{\circ}$ 243, a coordenação e execução da Política Cartográfica Nacional, que resulta nas exigibilidades para execução do mapeamento sistemático do espaço territorial brasileiro.

Quanto às funções das organizações vinculadas à Concar, algumas se destacam. O IBGE é incumbido pelas atividades de levantamentos de informações, modelagem e estruturação dos dados espaciais. Sua participação na Comissão talvez seja a de maior destaque, uma vez que o órgão está presente em todas as deliberações que envolvem a infraestrutura de dados espaciais. ADSG, em segundo plano, participa da Comissão, definindo as normas para cartografia básica terrestre. Estas se referem à elaboração de documentos como a Especificação Técnica para Estruturação de Dados Geoespaciais Vetoriais (ET-EDGV), norma voltada ao mapeamento topográfico e geoinformações em grandes escalas, e o Manual T34-700, que define a simbologia do mapeamento topográfico.

Além dessas, cabe ao ICA e à DHN o gerenciamento das atividades relacionadas à cartografia aérea e aquelas que permitem as atividades de navegação, respectivamente. O ICA no apoio ao Sistema de Controle do Espaço Aéreo Brasileiro, e a DHN no apoio às atividades navais da hidrografia, oceanografia e meteorologia.

O IBGE, em conjunto com sua Comissão de Cartografia, ao definir as escalas-padrão para o mapeamento do país como as de 1:1.000.000; 1:250.000; 1:100.000; 1:50.000; e 1:25.000, admite que a as feições a serem representadas pelo mapeamento sistemático é tal que a continuidade, homogeneidade e articulação das cartas deve se dar até a escala 1:25.000. Nesse ponto, ao analisarmos a importância da definição da escala para diferentes atividades, projetos e planejamento, verificamos que o mapeamento sistemático não tem obrigatoriedade de representar feições inferiores a aproximadamente cinco metros, já que atividades cartográficas apresentadas em escalas maiores que 1:25.000 não são regidas por normativas e especificações técnicas definidas pela referida Comissão.

Apesar de definido nas escalas de 1:25.000 a 1.1.000.000, até o ano de 2017, apenas 5\% do território nacional possuía recobrimento em escala de 1:25.000 (SLUTER et al., 2018). Essa deficiência, entre outras, se dá pelo não atendimento a um princípio básico da elaboração de bases cartográficas: defini-las de forma a permitir sua atualização. Em geral, sempre que há necessidade de atualizar um mapeamento, isso ocorre como se não existisse qualquer referência cartográfica da região. Após o término do novo mapeamento, por vezes o anterior é descartado. A Tabela 1 apresenta um 
panorama do território mapeado em função das diferentes escalas do mapeamento sistemático brasileiro.

Tabela 1. Porcentagem de recobrimento segundo escalas definidas para o mapeamento sistemático brasileiro.

\begin{tabular}{cc}
\hline Escala & $\begin{array}{c}\text { Percentual mapeado } \\
\text { do território brasileiro }\end{array}$ \\
\hline $1: 1.000 .000$ & $100 \%$ \\
$1: 250.000$ & $81 \%$ \\
$1: 100.000$ & $91 \%$ \\
$1: 50.000$ & $24 \%$ \\
$1: 25.000$ & $5 \%$ \\
\hline
\end{tabular}

Fonte: Adaptado de Sluter (2018).

Outro aspecto atual do mapeamento básico brasileiro é a busca pela definição de uma infraestrutura capaz de processar, armazenar e distribuir dados geográficos em um contexto nacional, já que, em diversas ocasiões, percebe-se a duplicidade de informação em diferentes esferas. Tais objetivos, entretanto, só podem ser considerados válidos se existir uma padronização ou, ao menos, recomendações para aquisição e disponibilização dos dados geoespaciais por parte dos produtores de cartografia. Só assim os dados oriundos de diferentes instituições poderão ser organizados para compor o mapeamento topográfico brasileiro.

Essa infraestrutura, denominada Infraestrutura Nacional de Dados Espaciais (Inde), instituída pelo Decreto $\mathrm{n}^{\circ}$ 6.666, de 27 de novembro de 2008, vem sendo disseminada nas esferas federal, estadual e municipal, buscando adequá-las para que se faça proveito das informações existentes nas respectivas instituições relacionadas. Em fase de adaptação e em virtude do grande número de instituições que na atualidade estão envolvidas na produção e distribuição de dados geoespaciais, em diferentes formatos, as referidas normas e padrões buscam garantir a interoperabilidade entre sistemas diversos, para facilitar o compartilhamento dos dados entre as organizações (CONGAR, 2009).

Diante disso, é necessário que os dados geoespaciais atendam aos chamados padrões de metadados que permitam sua estruturação em um banco de dados, visando a identificar o produtor e a responsabilidade técnica de produção; padronizar a terminologia utilizada; garantir a transferência de dados; viabilizar a integração de informações; identificar a qualidade da informação geográfica e subsidiar a análise do usuário quanto à adequação a suas aplicações; garantir os requisitos mínimos de divulgação e uso dos dados geoespaciais.

\section{MaPeAmento SISTEMÁTICO ALEMÃo}

Apesar de cada estado federado definir as regras de seu mapeamento, a Alemanha possui um Comitê que coordena as atividades de levantamento e representação territorial. Basicamente, o denominado Comitê das Repartições de Cadastro, Cartografia e Agrimensura dos Estados da República Federal da Alemanha (AdV), ou Arbeitsgemeinschaft der Vermessungverwaltungen der Länder der Bundesrepublick Deutschland, criado já no pós-guerra, em 1948, possui duas funções correlatas: evitar que as atividades de mapeamento dos diferentes estados fluam em direções opostas e permitir que os esforços realizados por cada estado constituam o mapeamento de referência nacional alemão (ASBEGK et al., 2007).

Entre os atores que compõem o AdV, estão os representantes técnicos de cada estado federado; e os Ministérios Federal do Interior, da Defesa, dos Transportes, da Construção Civil e do Desenvolvimento Urbano. Além destes, são membros convidados do Comitê a Comissão Alemã de Geodésia (DGK) e o Comitê Federal para Desenvolvimento Sustentável (FIGUR, 2012).

Em analogia ao Brasil, o AdV possui em suas especificações algumas semelhanças às políticas de mapeamento definidas pela Concar. Segundo a Associação Federal dos Engenheiros Agrimensores e Cartógrafos (Bundesverband der Diplomingenieure für Vermessungswesen - BDV), é obrigação do AdV: tratar questões relacionadas à manutenção e criação de referenciais geodésicos; levantamentos cadastrais de imóveis; desenvolvimento de sistemas de informação geográfica; metadados; e padrões para geotopografia.

Mesmo se tratando de recomendações, as especificações do AdV podem passar a oficiais e obrigatórias em um contexto nacional. Isso acontece quando há consenso comum entre os integrantes do referido Comitê. A articulação e as especificações para elaborar as cartas topográficas em diferentes escalas, em função da generalidade e significância, são exemplo de recomendação obrigatória da $\mathrm{AdV}$ para todos os estados federados (BDV, 1995). Um panorama geral das atividades de mapeamento realizadas por diferentes atores na Alemanha é apresentado na Figura 1. 
Figura 1. Visão geral dos atores envolvidos no mapeamento de referência alemão.

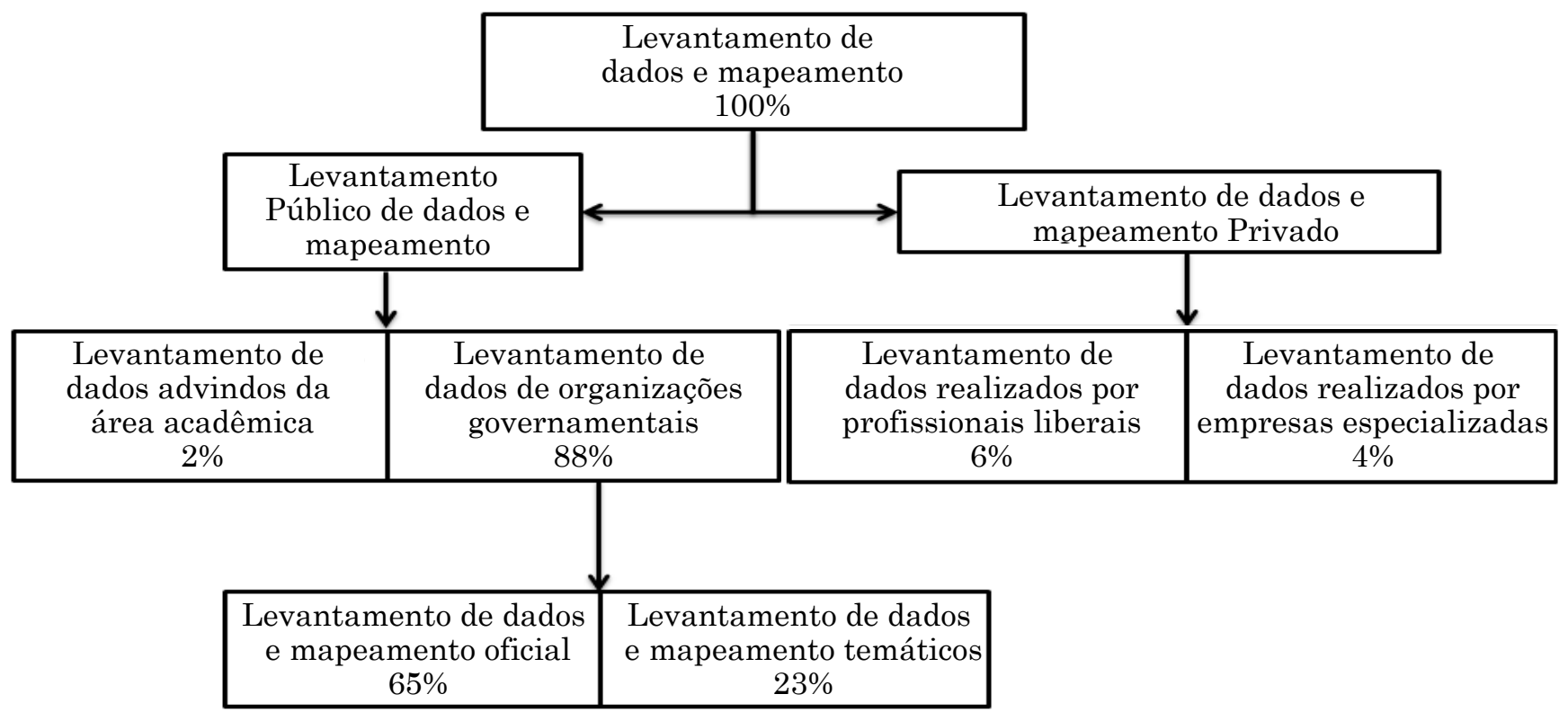

Fonte: Adaptado de Kummer (2006).

Conforme Kummer (2006), pode-se identificar uma estrutura de três níveis: um superior, de competência da União; o intermediário, onde se encontram os departamentos estaduais de Cadastro, Agrimensura e Cartografia, responsáveis pelas respectivas gestões técnicas do mapeamento; e as repartições regionais de Cadastro. Neste terceiro nível, uma analogia com os municípios brasileiros pode ser feita a partir da seguinte indagação: os dados dos cadastros municipais poderiam ser utilizados para compor o mapeamento sistemático da nação?

\section{Importância dos cadastros municipais na composição do mapeamento germânico}

Os trabalhos do AdV são divididos em quatro frentes técnicas que buscam apoiar as definições dos estados federados. São elas: Referência Geográfica; Geotopografia; Cadastro de Imóveis; e Técnicas de Informação e Comunicação. Segundo o AdV, os dados tratados pela Geotopografia, ou seja, dados visíveis da superficie terrestre, e os tratados pela frente de Cadastro de Imóveis, compreendem as informações geoespaciais básicas do mapeamento alemão. Entre outras, cabe ao Cadastro Imobiliário, segundo o Comitê AdV:

- dar a base necessária para composição da Infraestrutura de dados Geoespaciais da Alemanha (GDI-DE);
- servir como base espacial para diversas outras áreas, entre elas as relacionadas ao planejamento e ordenamento territorial nacional e urbano.

Uma vez reunidos na GDI-DE, os dados espaciais de diversos órgãos permitem compor o mapeamento de referência do país. Sendo a estrutura de competência da AdV, o mapeamento se trata, então, de um projeto conjunto dos governos federal, estaduais e locais. Ao colocar o Cadastro Imobiliário como informação geoespacial básica, a República Federal da Alemanha designa como fundamental sua informação na composição da infraestrutura de dados espaciais.

De responsabilidade dos estados federados, a execução dos levantamentos que dão origem aos produtos cartográficos oficias da União se dá pela vetorização de ortofotos geradas a partir de voos coordenados também pelos estados. Visando à continuidade do mapeamento, os voos são realizados com intervalos máximos de cinco anos. Os ortomosaicos são arquivados em um banco de dados de série temporal, destinado consequentemente, a análises temporais.

Já as feições imobiliárias, de competência dos órgãos locais, são levantadas individualmente, em sua maioria. Sejam por técnicas geodésicas ou topográficas, suas coordenadas são amarradas à rede de referência geodésica. 
Dessa forma, a georreferência a elas atribuída dá suporte ao georreferenciamento das ortofotos.

Kummer (2006) apresenta três atores envolvidos diretamente na execução do levantamento espacial imobiliário: as repartições públicas de Cadastro de Cartografia e Agrimensura dos estados federados; órgãos públicos ligados a autoridades municipais relacionados a atividades de Agrimensura e Cadastro; e engenheiros agrimensores habilitados e credenciados para tal atividade.

Para que os Cadastros Imobiliários sejam disponibilizados em um contexto nacional, é necessário que estes estejam armazenados em uma mesma plataforma. Uma vez que o Cadastro Imobiliário é formado por mapas das propriedades e que compõem também o registro imobiliário destas, são as informações dos registros imobiliários que fomentam essa plataforma. Desde o ano de 2015, um único sistema de informação, o Sistema de Informação cadastral do Registro Imobiliário, ou Steht für Amtliches Liegenschaftskatasterinformationssystem (Alkis), passou a receber as informações supracitadas. A Figura 2 apresenta a evolução do uso do Cadastro no mapeamento alemão.

Figura 2. Evolução da utilização do Cadastro no mapeamento alemão.

\begin{tabular}{|l|l|l|l|}
\hline $\begin{array}{c}\text { Cadastro com fins de } \\
\text { arrecadação tributária }\end{array}$ & $\begin{array}{c}\text { Cadastro para o } \\
\text { registro imobiliário }\end{array}$ & $\begin{array}{c}\text { Cadastro voltado ao } \\
\text { planejamento urbano e rural }\end{array}$ & $\begin{array}{l}\text { Cadastro direcionado ao } \\
\text { mapeamento sistemático }\end{array}$ \\
\hline & & & 2000 \\
\hline & & 1934 &
\end{tabular}

Fonte: Adaptado de Figur (2012).

\section{Plataforma única para centralizare unificar informações geoespaciais}

É disponibilizada a partir de um sistema de referência único. Entre os atributos das unidades imobiliárias em âmbito nacional estão um identificador único (ID); as coordenadas oficiais do imóvel, detectadas com segurança dentro da geometria do edifício (centroide); e suas coordenadas referenciadas ao sistema de referência ETRS89/UTM.

O ETRS89 se materializa a partir de pontos de controle planialtimétricos, levantados inclusive gravimetricamente. Como pontos oficiais, estes são mantidos pela Agência Federal de Cartografia e Geodésia (BKG), órgão federado responsável por tarefas ligadas ao campo da geoinformação e geodésia. Amarrar os imóveis urbanos e rurais à rede geodésica é uma das funções da rede, sendo suas coordenadas e demais atributos registrados $\mathrm{e}$ armazenados em um sistema denominado Registro de Controle de Pontos do Sistema de Informação (Amtliches Festpunktinformationssystem - AFIS).

O vínculo dos dados espaciais do ALKIS com os dados do AFIS alimenta o banco de dados do Sistema de Informação Cartográfico e Topográfico Oficial (Amtliches Topographisch-Kartographisches Informationssystem - ATKIS). No ATKIS estruturam-se as informações espaciais que, reunidas, compõem o mapeamento de referência da Alemanha.
Os mapas topográficos são disponibilizados em formato raster, mas podem também, a pedido dos usuários, ser disponibilizados em camadas vetoriais. A responsabilidade por sua distribuição, nas escalas $1: 10.000 ; 1: 25.000 ; 1: 50.000$ e 1:100.000, é dos próprios estados federados. Além desses, são produtos do mapeamento de referência modelos digitais de terreno e ortofotos digitais com resoluções espaciais que chegam a 20 centímetros.

\section{Conclusão}

Uma vez que recai sobre o IBGE a obrigatoriedade do mapeamento em escalas até 1:25.000, em escalas superiores há uma atuação forte de empresas e profissionais liberais atuando no mapeamento do espaço territorial brasileiro. Isso ocorre devido às necessidades privadas ou de entidades públicas da esfera estadual ou municipal, nos casos em que a produção cartográfica exige maior detalhamento.

Diferentemente do que ocorre na Alemanha, essas informações, que poderiam ser generalizadas para compor o mapeamento de referência brasileiro, em sua maioria ficam restritas ao uso das empresas e órgãos contratantes. Uma vez que recomendações da Concar fossem atendidas nos processos de produção de dados 
geoespaciais, como o atendimento aos padrões de metadados; georreferenciamento das feições ao Sistema Geodésico Brasileiro; utilização de simbologia adequada ao Manual T34-700; entre outras, uma analogia com o caso alemão poderia ser verificada. Isso porque, apesar de recomendações, as especificações do AdV estão presentes em todos os trabalhos germânicos relacionados à cartografia.

A mesma discussão pode ser aprofundada na verificação da utilidade dos Cadastros Municipais germânicos como base para o mapeamento de referência. Assim como as Diretrizes para o Cadastro Territorial Multifinalitário, não compete ao AdV determinar instruções, mas recomendações para as atividades públicas oficiais de Cadastro, Cartografia e Agrimensura na Alemanha. Nesse contexto, a cartografia gerada pelos municípios brasileiros poderia, sem dúvida, integrar o conjunto de dados de referência.

Entretanto, os cadastros municipais, mesmo regidos por diretrizes propostas pelo Ministério das Cidades, ainda não possibilitam adequadamente a disponibilidade, acessibilidade, integração e distribuição de informação voltada à administração territorial pública (PAIVA, 2016). Diante disso, sua utilização em contexto nacional, como no mapeamento de referência, ainda não é apropriado.

Analisando, porém, os dados rurais georreferenciados oriundos de uma base como a do Instituto Nacional de Colonização e Reforma Agrária (Incra), por exemplo, a relação com os dados coletados por agrimensores autônomos na Alemanha é direta. Isso é visível já que, assim como no país europeu, no Brasil é comum a execução dos levantamentos que delimitam as propriedades rurais por profissionais e empresas particulares de topografia e agrimensura. Sendo esses levantamentos validados por órgão oficial e federal, essa é uma discussão que poderia vir à tona: os produtos do georreferenciamento de imóveis rurais serviriam como base para a execução do mapeamento de referência nacional?

Além disso, outra questão correlata corresponde à vinculação de profissionais autônomos de agrimensura devidamente credenciados às atividades de mapeamento. Comprovada sua habilitação, assim como ocorre na Alemanha, esses poderiam minimizar a deficiência operacional decorrente da falta de pessoal especializado nos processos de levantamento e implantação do referencial geodésico necessário aos processos de mapeamento?

Por fim, em função dos desenvolvimentos tecnológicos verificados em ambos os países, voltados ao armazenamento e à integração de dados oriundos de diversas fontes, sabe-se que entre as maiores dificuldades em se unificar toda essa informação em prol de um mapeamento integrado de referência no Brasil não está a questão tecnológica. Resta, nesse contexto, que as orientações definidas pelas agências responsáveis pelas Políticas da Cartografia Nacional sejam atendidas pelos produtores de informação geoespacial de todas as esferas.

\section{REFERÊNCIAS}

ASBECK, M. et al. Vermessung und geoinformation: fachwissen des vermessungstechnikers. 10. ed. Düsseldorf: Selbsverlag Michael Gärtner, 2007.

BUNDESVERBAND DER DIPLOMINGENIEURE FÜR VERMESSUNGSWESEN. Landesvermessung und Kartographie. Hannover: BDV, 1995.

GONGAR - GOMISSÃO NAGIONAL DE CARTOGRAFIA. Perfil de metadados geoespaciais do Brasil (Perfil MGB). Rio de Janeiro: Concar, 2009.

FIGUR, R. L. Análise comparativa entre o sistema o sistema cadastral da Alemanha e as diretrizes para o cadastro territorial multifinalitário brasileiro. 2011. Dissertação (Mestrado em Engenharia Civil) - Universidade Federal de Santa Catarina, Florianópolis, 2011.

HAWERK, W. Cadastre for the 21st century: German way. In: INTERNATIONAL FIG CONGRESS: SHAPING THE GHANGE, 23., 2006, Munich. Proceedings [...]. Munich: FIG-OICRF, 2006. p. 1-12. Disponível em: https://bit.ly/3fUL4Q2. Acesso em: 10 jun. 2017.

KUMMER, K. The official surveying and mapping in Germany and its contribution to the National SDI (GDI-DE). In: INTERNATIONAL FIG CONGRESS: SHAPING THE CHANGE, 23., 2006, Munich. Proceedings [...]. Munich: FIG-OICRF, 2006. p. 1-12.

MENDONÇA, A. L. A.; SLUTER, C. R. Análise da relação entre ensino e pesquisa em Ciências Geodésicas e a cobertura do mapeamento sistemático no Brasil. Revista Brasileira de Cartografia, Monte Carmelo, v. 63, p. 1-10, 2011. Edição especial. 
PAIVA, C. A. Proposta de integração entre os

Dados do Gadastro Imobiliário Urbano e do

Registro de Imóveis. 2016. Dissertação (Mestrado em Ciências Geodésicas) - Universidade Federal do Paraná, Curitiba, 2016.

PERMANENT GOMMITTEE ON GIS INFRASTRUGTURE FOR ASIA E THE PACIFIC.

Cadastral Template 2003. Country report: Germany. [S. l.]: PCGIAP, 2003.
SLUTER, G. R. et al. A proposal for topographic map symbols for large-scale maps of urban areas in Brazil. Cartographic Journal, Wales, v. 55, n. 4, p. 362-377, 2018.

SPIELMAN, S. E. Spatial collective intelligence? Credibility, accuracy, and volunteered geographic information. Gartography and Geographic Information Science, Abingdon, v. 41, n. 2, p. 115-124, 2014. 